\title{
The ACE Gene Insertion/Deletion Polymorphism and Cerebrovascular Diseases in Uzbek Patients with Arterial Hypertension
}

\author{
Nargiza U. Makhkamova, PhD; Gulnoz A. Khamidullaeva, PhD, ScD* \\ The Republican Specialized Center of Cardiology, Tashkent, Uzbekistan
}

\begin{abstract}
The aim of the present study was to investigate the association between the ACE gene I/D polymorphism and the development of hypertensive encephalopathy (HE) in Uzbek patients with hypertension (HT).

Materials and methods: The study included 91 male patients aged from 32 to 74 years (mean age 52.5 \pm 9.2 ) with HT Grade 1, 2 and 3 (ESH/ESC, 2013) and presence of HE. All patients were checked on office BP using Korotkov's method and ambulatory blood pressure monitoring (ABPM). Intima-media thickness (IMT) of the carotid artery was measured by a 7.5 MHz high-resolution ultrasound. Genomic DNA was isolated from peripheral blood using the Diatom ${ }^{\mathrm{TM}}$ DNA Prep 200 Kit according to the manufacturer's protocol. ACE gene I/D polymorphism genotypes were determined by PCR.

Results: Among HT patients with HE, we have identified a statistically significant predominance of ID genotype carriers $(65.9 \%)$ against carriers of the II genotype $(18.7 \%)$ and DD genotype $(15.4 \%)(P=0.000)$; the frequency of I and D alleles was $51.6 \%$ and $48.4 \%$, respectively $(P>0.05)$. Comparative analysis showed a possible association between the ID genotype/D allele and HE development in HT patients, according to the general model $(\mathrm{OR}=6.36 ; 95 \% \mathrm{CI}$ : $3.04-13.31 ; P=0.000)$ and multiplicative model $(\mathrm{OR}=2.02 ; 95 \% \mathrm{CI}: 1.25-3.27 ; P=0.004)$ of inheritance. High grades of HT were predominant in carriers of the DD genotype. IMT was significantly higher in carriers of the DD genotype than in carriers of the II and ID genotypes. The carriage of D allele was associated with the highest levels of TC, TG, and VLDL-C. Carriers of the DD genotype were characterized by higher values of daytime SBP, nighttime SBP variability and nighttime SBP load. (Int J Biomed. 2016;6(3):174-178.).
\end{abstract}

Key Words: hypertension • cerebrovascular disease • ACE Gene I/D polymorphism • ambulatory blood pressure monitoring

\section{Abbreviations}

ABPM, ambulatory blood pressure monitoring; ACE, angiotensin-converting enzyme; BP, blood pressure; DBP, diastolic BP; HDL-C, high-density lipoprotein cholesterol; IMT, intima-media thickness; I/D, insertion/deletion; LDL-C, low-density lipoprotein cholesterol; RAS, renin-angiotensin system; SBP, systolic BP; TC, total cholesterol; TG, triglyceride; TIA, transient ischemic attack; VLDL-C, very low-density lipoprotein cholesterol.

\section{Introduction}

Hypertension (HT) is a well-established risk factor for cardiovascular diseases. An estimated 17.5 million people died from cardiovascular diseasesin 2012, representing 31\% of all global deaths. Of these deaths, an estimated 7.4 million were due to coronary heart disease and 6.7 million were due to stroke. ${ }^{[1]}$ High BP multiplies the risk for stroke as much as four-

*Corresponding author: Gulnoz A. Khamidullaeva, PhD, $S c D$. The Republican Specialized Center of Cardiology, Tashkent, Uzbekistan.E-mail: gulnoz0566@mail.ru fold. The risk of cerebral hemorrhage in hypertensive patients is 3.9 times higher than in non-hypertensive individuals. ${ }^{\left[{ }^{[2]}\right.}$ Hypertensive encephalopathy (HE) refers to the transient migratory neurologic symptoms that are associated with the malignant hypertensive state in a hypertensive emergency. The most common cause of hypertensive encephalopathy is abrupt blood pressure elevation above cerebral autoregulation limits. HE is a life-threatening disorder characterized by severe neurological manifestations, including lowered consciousness, lethargy, confusion, blindness and seizures, in the absence of other causes. Brain MRI scans have shown a pattern of typically posterior (occipital greater than frontal) brain edema 
that is reversible. This usually is termed reversible posterior leukoencephalopathy or posterior reversible encephalopathy syndrome (PRES). ${ }^{[3]}$

Currently, increasing attention is being paid to genetic factors in the development of cerebrovascular diseases (CDs), and the value of various RAS genes has been investigated in many studies. However, ACE gene I/D polymorphism has not been studied in hypertensive patients with chronic CDs of Uzbek nationality.

The aim of the present study was to investigate the association between ACE gene I/D polymorphism and HE development in Uzbek patients with HT.

\section{Materials and methods}

The study included 91 male patients aged from 32 to 74 years (mean age 52.5 \pm 9.2 ) with HT Grade 1, 2 and 3 (ESH/ ESC, 2013 $)^{[4]}$ and presence of HE. Average duration of HT was $9.2 \pm 7.5$ years. HE Stages 1 and 2 were detected in $34.3 \%$ and $48.1 \%$ of cases; HE with TIA was detected in $17.6 \%$ of patients. The control group included 60 healthy, age-matched male volunteers. The study was approved by the Republican Specialized Center of Cardiology Ethics Committee and conducted in accordance with the ethical principles stated in the Declaration of Helsinki. Written informed consent was obtained from each patient.

Exclusion criteria were: symptomatic HT; acute coronary syndrome, stable angina pectoris Class III-IV, chronic heart failure (NYHA FC>II), cardiac arrhythmia, history of stroke and myocardial infarction within previous 12 months, renal impairment, diabetes mellitus, severe comorbidities.

Body mass index (BMI) was calculated by weight $(\mathrm{kg})$ divided by the squared height $(\mathrm{m})\left(\mathrm{kg} / \mathrm{m}^{2}\right)$. Office BP was determined in the reclining position using Korotkov's method and a mercury sphygmomanometer after 5-minute rest and an average of three readings.

ABPM was carried out on the non-dominant arm using TONOPORT V-General Electric (Germany). The device was set to obtain BP readings at 15 min intervals during the day $(7 \mathrm{am}-11 \mathrm{pm})$ and at $30 \mathrm{~min}$ intervals during the night $(11 \mathrm{pm}-$ $7 \mathrm{am})$. The recording was then analyzed to obtain $24 \mathrm{~h}$, daytime and nighttime average SBP, DBP and heart rates. Nocturnal dipping was defined as a reduction in average SBP and DBP at night greater than $10 \%$ compared with average daytime values.$^{[5]}$

Blood levels of TC, HDL-C and TG were determined using an A-25 Biosystems Autoanalyzer (DAYTONA) and the "RENDOX" sets. The atherogenic coefficient was defined by the following formula: $\mathrm{AC}=(\mathrm{TG}-\mathrm{HDL}-\mathrm{C}) / \mathrm{HDL}-\mathrm{C}(\mathrm{RU})$.

IMT of the carotid artery was measured by a $7.5 \mathrm{MHz}$ high-resolution ultrasound (EnVisorC®).

Genomic DNA was isolated from peripheral blood using the Diatom ${ }^{\mathrm{TM}}$ DNA Prep 200 Kit according to the manufacturer's protocol. ACE gene I/D polymorphism genotypes were determined by $\mathrm{PCR} .{ }^{[6]}$ Reactions were performed with 10 pmol of each primer:

F: 5'-CTG GAG ACC ACT CCC ATC CTT TCT-3'

R: 5'-GAT GTG GCC ATC ACA TTC GTC AGA T-3'.
PCR products were analyzed on $2 \%$ agarose gels after staining with ethidium bromide and were visualized using a UV transilluminator. Two alleles were identified: a 490-bp fragment $I$ (with the insertion) and a 190-bp fragment $D$ (without the insertion). In heterozygous samples, two bands (490 bp and $190 \mathrm{bp}$ ) were detected. To avoid mistyping of heterozygotes (ID) DNA samples identified as a DD genotype were subsequently amplified with second set of primers designed for the insertion specific allele.

Depending on carriage of the I/D polymorphic marker, all patients were divided into three groups: Group 1 included 17 patients (II genotype carriers), Group 2 included 60 patients (ID genotype carriers), and Group 3 included 14 patients (DD genotype carriers).

Statistical analysis was performed using StatSoft Statistica v6.0. Baseline characteristics were summarized as frequencies and percentages for categorical variables and as mean $\pm \mathrm{SD}$ for continuous variables. The genotype frequency distribution for each variant was separately tested for Hardy-Weinberg equilibrium (HWE) with a chi-square test in the patient and control groups. Odds ratios (ORs) and 95\% confidence intervals (CIs) were calculated. Multiple comparisons were performed with one-way ANOVA and post-hoc Tukey HSD test. A probability value of $P<0.05$ was considered statistically significant.

\section{Results}

In the group as a whole, the mean sitting office DBP and SBP were $170.5 \pm 24.6 \mathrm{mmHg}$ and $100.4 \pm 10.4 \mathrm{mmHg}$, respectively. The average BMI was $28.9 \pm 4.1 \mathrm{~kg} / \mathrm{m}^{2} ; 54.5 \%$ of patients were overweight and $30.8 \%$ of patients suffered from first or second degree obesity (BMI $>30 \mathrm{~kg} / \mathrm{m}^{2}$ ). Among HT patients with HE, we have identified a statistically significant predominance of ID genotype carriers $(65.9 \%)$ against carriers of the II genotype (18.7\%) and DD genotype (15.4\%) $(P=0.000)$; the frequency of $\mathrm{I}$ and $\mathrm{D}$ alleles was $51.6 \%$ and $48.4 \%$, respectively $(\mathrm{P}>0.05)$. In control group, the frequency of II, ID and DD genotypes was $56.7 \%, 23.3 \%$ and $20 \%$, respectively $(P=0.000)$; the frequency of I and $\mathrm{D}$ alleles was $68.3 \%$ and $31.7 \%$, respectively $(P=0.000)$ (Fig.1.). In both groups, genotypes were in Hardy-Weinberg equilibrium.

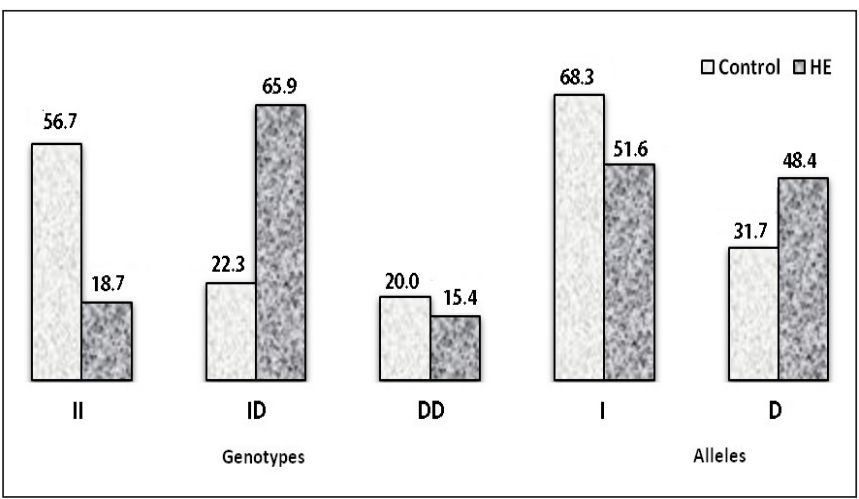

Fig.1. The frequency (\%) of genotypes and alleles of the ACE gene I/D polymorphism in Uzbek patients with HE. 
Comparative analysis showed a possible association between the ID genotype/D allele and HE development in HT patients, according to the general model $(\mathrm{OR}=6.36 ; 95 \% \mathrm{CI}: 3.04-13.31$; $P=0.000)$ and multiplicative model $(\mathrm{OR}=2.02 ; 95 \% \mathrm{CI}: 1.25$ $-3.27 ; P=0.004)$ of inheritance. No significant relation was observed between the I/D polymorphism and BMI. We found an association between the office SBP and ACE gene I/D polymorphism. Carriers of the II genotype had SBP levels corresponding to Grade $1 \mathrm{HT}$; carriers of the ID and DD genotypes had SBP levels corresponding to Grade 2 HT (Table 1). We did not observe notable differences in office DBP levels between genotypes. High grades of HT were predominant in carriers of the DD genotype (Fig.2.).

\section{Table 1.}

Baseline characteristics of HE patients depending on the ACE gene I/D polymorphism

\begin{tabular}{|c|c|c|c|c|c|c|c|}
\hline \multirow{2}{*}{ Idic } & \multirow{2}{*}{$\begin{array}{c}\text { II, } \mathrm{n}=17 \\
\text { (1) }\end{array}$} & \multirow{2}{*}{$\begin{array}{c}\text { ID, } n=60 \\
(2)\end{array}$} & \multirow{2}{*}{$\begin{array}{c}\text { DD, } n=14 \\
\text { (3) }\end{array}$} & \multirow{2}{*}{$P^{*}$} & \multicolumn{3}{|c|}{ Tukey HSD test } \\
\hline & & & & & $P_{1-2}$ & $P_{l-3}$ & $P_{2-3}$ \\
\hline Age,y & 0 & 53. & 52.3 & 0.607 & .586 & 0.88 & .937 \\
\hline BMI, & 29.5 & 28.5 & 2 & 0.464 & 854 & 0.443 & 0.5 \\
\hline $\mathrm{HT}^{\wedge}, \mathrm{y}$ & 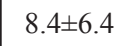 & 9.0 & 9.3 & 0.360 & 0.953 & 0.395 & 0.389 \\
\hline SBP, 1 & (153. & 175. & 174. & 0.009 & 0.007 & 0.0 & 0.97 \\
\hline DBP,mmHg & $97.6 \pm 12.4$ & $101.3 \pm 10.3$ & $100.7 \pm 7.3$ & 0.431 & 0.398 & 0.685 & 0.979 \\
\hline IMT,mm & $0.85 \pm 0.24$ & $0.99 \pm 0.30$ & $1.25 \pm 0.28$ & 0.001 & 0.184 & 0.001 & 0.00 \\
\hline
\end{tabular}

$\wedge$-duration; $P^{*}$ - for ANOVA

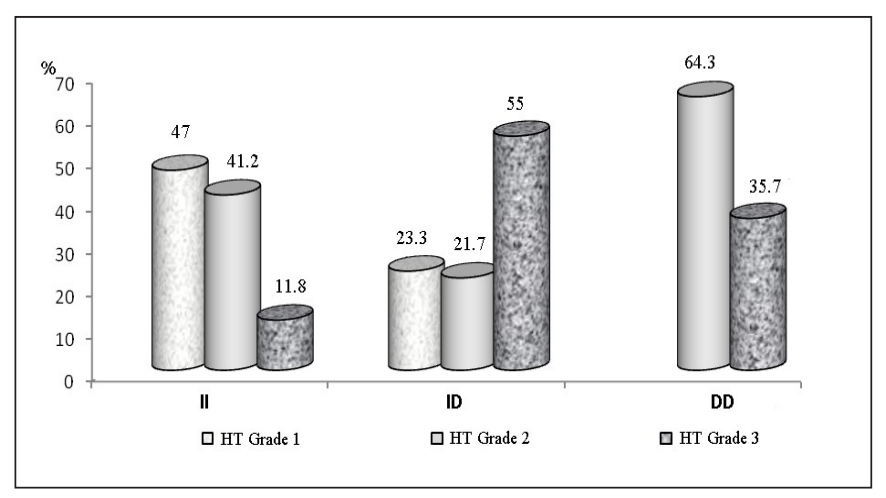

Fig.2. The distribution of HT grades depending on the ACE gene I/D polymorphism

IMT of the carotid artery exceeded standard measures in all patients. In the comparative aspect, IMT was significantly higher in carriers of the DD genotype than in carriers of the II and ID genotypes. Dyslipidemia was found in $62.6 \%$ patients. The carriage of D allele was associated with the highest levels of TC, TG, and VLDL-C (Table 2).

According to ABPM data, we found a significant increase in indicators of average daytime and nighttime SBP and DBP against the standard indices. Carriers of the DD genotype were characterized by higher values of daytime SBP, nighttime SBP variability and nighttime SBP load (Table 3). Of 91 patients, $60 / 65.9 \%$ showed a drop in SBP/ $\mathrm{DBP}<10 \%$ during nighttime sleep and were categorized as non-dippers; the remaining patients were categorized as dippers (13/14.3\%), over-dippers $(6 / 6.6 \%)$, and night-peakers $(12 / 13.2 \%)(p=0.000)$. The statistical prevalence of nondippers was significant for all genotypes (Fig.3).

\section{Table 2.}

Blood lipid spectrum of HE patients depending on the ACE gene I/D polymorphism

\begin{tabular}{|l|c|c|c|c|c|c|c|}
\hline \multirow{2}{*}{ Indices $^{\wedge}$} & \multirow{2}{*}{$\mathrm{II}, \mathrm{n}=17$} & $\mathrm{ID}, \mathrm{n}=60$ & $\mathrm{DD}, \mathrm{n}=14$ & & \multicolumn{3}{|c|}{ Tukey HSD test } \\
& $(1)$ & $(2)$ & $(3)$ & $P^{*}$ & $P_{I-2}$ & $P_{1-3}$ & $P_{2-3}$ \\
\hline TC & $208.2 \pm 36.1$ & $256.3 \pm 41.3$ & $215.8 \pm 28.4$ & 0.000 & 0.000 & 0.850 & 0.002 \\
\hline TG & $142.5 \pm 58.7$ & $197.0 \pm 89.8$ & $212.2 \pm 75.4$ & 0.034 & 0.049 & 0.057 & 0.811 \\
\hline HDL-C & $42.4 \pm 6.2$ & $39.3 \pm 7.8$ & $39.1 \pm 7.0$ & 0.294 & 0.286 & 0.437 & 0.996 \\
\hline VLDL-C & $28.6 \pm 11.8$ & $40.4 \pm 18.6$ & $41.4 \pm 15.8$ & 0.038 & 0.037 & 0.102 & 0.979 \\
\hline LDL-C & $137.2 \pm 30.8$ & $139.1 \pm 37.3$ & $134.9 \pm 27.6$ & 0.915 & 0.979 & 0.982 & 0.913 \\
\hline AC, RU & $4.0 \pm 1.0$ & $4.8 \pm 1.7$ & $4.6 \pm 0.8$ & 0.153 & 0.129 & 0.506 & 0.893 \\
\hline
\end{tabular}

^- TC, TG, HDL-C VLDL-C and VLDL-C in mg/dL

$P^{*}$ - for ANOVA

Table 3.

$A B P M$ indices in $H E$ patients depending on the ACE gene $I / D$ polymorphism

\begin{tabular}{|c|c|c|c|c|c|c|c|}
\hline \multirow{2}{*}{ Indices } & \multirow{2}{*}{$\begin{array}{c}\text { II, } n=17 \\
\text { (1) }\end{array}$} & \multirow{2}{*}{$\begin{array}{c}\mathrm{ID}, \mathrm{n}=60 \\
(2)\end{array}$} & \multirow{2}{*}{$\begin{array}{c}\mathrm{DD}, \mathrm{n}=14 \\
(3)\end{array}$} & \multirow{2}{*}{$P^{*}$} & \multicolumn{3}{|c|}{ Tukey HSD test } \\
\hline & & & & & $P_{1-2}$ & $P_{1-3}$ & $P_{2-3}$ \\
\hline & \multicolumn{7}{|c|}{ Daytime BP, $\mathrm{mmHg}$} \\
\hline SBP & $152.3 \pm 10.6$ & $158.2 \pm 14.7$ & $167.7 \pm 15.2$ & 0.012 & 0.286 & 0.009 & 0.066 \\
\hline \multirow[t]{2}{*}{ DBP } & $92.8 \pm 9.7$ & $94.1 \pm 10.1$ & $97.3 \pm 9.1$ & 0.430 & 0.882 & 0.421 & 0.522 \\
\hline & \multicolumn{7}{|c|}{ Nighttime BP, mm.Hg } \\
\hline SBP & $136.4 \pm 12.6$ & $143.1 \pm 17.7$ & $145.3 \pm 12.0$ & 0.240 & 0.290 & 0.282 & 0.890 \\
\hline \multirow[t]{2}{*}{ DBP } & $78.4 \pm 6.0$ & $81.8 \pm 7.6$ & $82.6 \pm 7.5$ & 0.190 & 0.214 & 0.255 & 0.928 \\
\hline & \multicolumn{7}{|c|}{ Daytime BP variability, $\mathrm{mmHg}$} \\
\hline SBP & $12.9 \pm 2.7$ & $13.8 \pm 4.4$ & $15.3 \pm 3.2$ & 0.247 & 0.689 & 0.222 & 0.416 \\
\hline \multirow[t]{2}{*}{ DBP } & $11.7 \pm 3.1$ & $13.5 \pm 4.5$ & $14.4 \pm 5.7$ & 0.216 & 0.315 & 0.223 & 0.778 \\
\hline & \multicolumn{7}{|c|}{ Nighttime BP variability, $\mathrm{mmHg}$} \\
\hline SBP & $10.7 \pm 3.1$ & $12.9 \pm 3.8$ & $13.9 \pm 4.2$ & 0.045 & 0.088 & 0.052 & 0.642 \\
\hline \multirow[t]{2}{*}{ DBP } & 9.6 & $11.3 \pm 3.9$ & $12.7 \pm 4.4$ & 0.075 & 0.234 & 0.064 & 0.426 \\
\hline & \multicolumn{7}{|c|}{ Nocturnal BP fall, $\%$} \\
\hline SBP & $5.7 \pm 3.9$ & $4.9 \pm 5.7$ & $3.4 \pm 4.5$ & 0.471 & 0.844 & 0.448 & 0.602 \\
\hline \multirow[t]{2}{*}{ DBP } & $7.8 \pm 3.0$ & $6.3 \pm 6.8$ & $4.2 \pm 7.6$ & 0.302 & 0.672 & 0.271 & 0.515 \\
\hline & \multicolumn{7}{|c|}{ Daytime BP load, \% } \\
\hline SBP & $34.8 \pm 24.6$ & $51.1 \pm 31.0$ & $59.8 \pm 32.8$ & 0.060 & 0.128 & 0.062 & 0.598 \\
\hline \multirow[t]{2}{*}{ DBP } & $40.5 \pm 30.5$ & $48.2 \pm 30.2$ & $49.0 \pm 29.0$ & 0.624 & 0.622 & 0.714 & 0.995 \\
\hline & \multicolumn{7}{|c|}{ Nighttime BP load, \% } \\
\hline SBP & $48.6 \pm 30.4$ & $61.5 \pm 30.7$ & $74.5 \pm 23.0$ & 0.058 & 0.258 & 0.046 & 0.306 \\
\hline DBP & $56.0 \pm 31.4$ & $62.8 \pm 29.6$ & $66.4 \pm 21.9$ & 0.579 & 0.670 & 0.582 & 0.908 \\
\hline
\end{tabular}




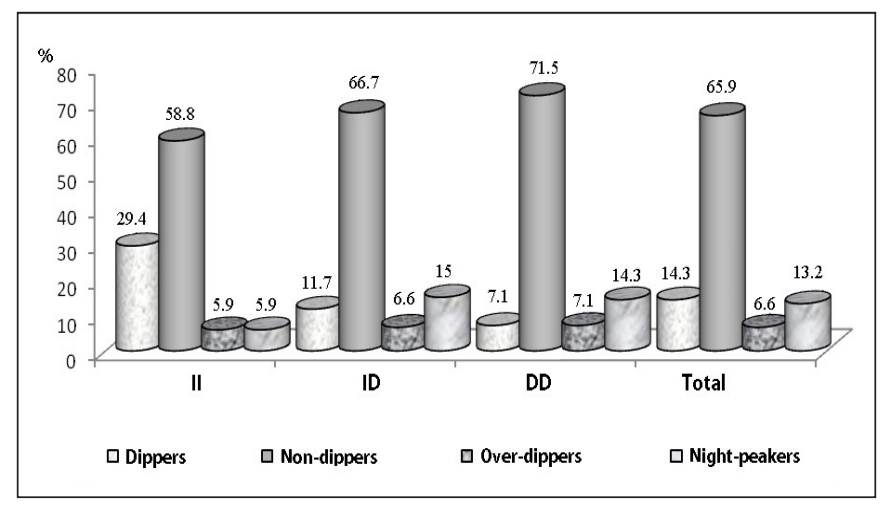

Fig.3 Circadian Variation of Blood Pressure depending on the ACE gene I/D polymorphism

\section{Discussion}

The results of our study revealed a significant association between the ID genotype and the D allele of ACE gene I/D polymorphism with a high risk of HE development in HT patients of Uzbek nationality.

A strong association between the DD genotype and the $\mathrm{D}$ allele with ischemic stroke (IS) was revealed in a number of studies, ${ }^{[7-10]}$ while others showed no such association. ${ }^{[11-14]}$ Siera et al. ${ }^{[15]}$ investigated a possible association between 3 different genetic polymorphisms of RAS and the presence of cerebral white matter lesions (WML) in 60 never-treated essential hypertensive patients (36 men, 24 women), aged 50 to 60 years, without clinical evidence of target organ damage. All patients underwent brain magnetic resonance imaging to establish the presence or absence of WML. The I/D ACE gene, the M235T angiotensinogen (AGT) gene, and the A1166C angiotensin II type 1 receptor gene polymorphisms were determined by standard polymerase chain reaction. Twentyfive hypertensive patients $(41.6 \%)$ were found to have WML on brain MRI. Significant association with the presence of WML was found only for ACE gene I/D polymorphism. The frequency of the DD genotype in patients with WML (64\%) was significantly higher than that observed in patients without WML $(28.6 \% ; P=0.022)$. The DD genotype OR for the presence of WML was 4.44 (95\%CI: 1.48-13.3). Likewise, the proportion of the D allele in patients with WML (74\%) was significantly higher $(P=0.014)$ than that observed in patients without WML (51.4\%). Authors concluded that the presence of the DD genotype and/or the D allele of the ACE gene may be a predisposing factor for developing WML in essential hypertensive patients.

Presumably, these observed variations could be attributed to the differences in ethnic composition of study subjects and study design. ${ }^{[16]}$ A recent meta-analysis revealed the $\mathrm{D}$ allele as a low-penetrance susceptibility marker for IS. ${ }^{[17]}$ It is possible that ACE gene $\mathrm{I} / \mathrm{D}$ polymorphism can modulate cerebrovascular risk only in combination with other risk factors, such as HE, hyperlipidemia, smoking, diabetes, and systemic atherosclerosis. In our study, we found a significant association between the ID allele and pronounced disorders in BP profile, high levels of TC, TG, VLDL-C, and IMT values.
The association between the DD genotype and a high degree of LVH and endothelial dysfunction in Uzbek HT patients was shown previously. ${ }^{[18-20]}$ Some studies ${ }^{[19,21,22]}$ have shown that the DD genotype is a potential risk factor for the development of carotid atherosclerosis with hemodynamically significant stenosis.

In conclusion, the carriage of the ID genotype and/or the D allele of the ACE gene may be a predisposing factor for developing HE in HT patients of Uzbek nationality. Among HT patients with HE, the presence of the ID and DD genotypes has been associated with a high degree of HT and IMT value in comparison with the II genotype. We found significant association between the DD genotype/D allele and pronounced disorders in daily BP profile, high levels of TC, TG, and VLDL-C. However, because of the small sample size, these results require confirmation in a larger study.

\section{Competing interests}

The authors declare that they have no competing interests.

\section{References}

1. WHO: Cardiovascular diseases (CVDs). Fact sheet, June 2016. http://www.who.int/mediacentre/factsheets/fs317/en/

2. Arboix A.Cardiovascular risk factors for acute stroke: Risk profiles in the different subtypes of ischemic stroke. World J Clin Cases. 2015;3(5):418-29.

3. Hinchey J, Chaves C, Appignani B, Breen J, Pao L, Wang A, et al. A reversible posterior leukoencephalopathy syndrome. N Engl J Med 1996;334:494-500.

4. Mancia G, Fagard R, Narkiewicz K, Redon J, Zanchetti A, Böhm M, et al. $2013 \mathrm{ESH} / \mathrm{ESC}$ guidelines for the management of arterial hypertension: the Task Force for the Management of Arterial Hypertension of the European Society of Hypertension (ESH) and of the European Society of Cardiology (ESC). Eur Heart J. 2013;34(28):2159-219.

5. Verdecchia P, Schillaci G, Guerrieri M, Gatteschi C, Benemio G, Boldrini F, Porcellati C. Circadian blood pressure changes and left ventricular hypertrophy in essential hypertension. Circulation. 1990;81:528-36.

6. Cambien F, Poirier O, Lecerf L, Evans A, Cambou J-P, Arveiller D, et al. Deletion polymorphism in the gene for angiotensin-converting enzyme is a potent risk factor for myocardial infarction. Nature. 1992;359:641-4.

7. Catto A, Carter AM, Barret JH, Stickland M, Bamford J, Davies JA. Angiotensin-converting enzyme insertion/deletion polymorphism and cerebrovascular disease. Stroke. 1996; 27(3):435-40.

8. Kalita J, Somarajan BI, Kumar B, Mittal B, Misra UK. A study of ACE and ADD1 polymorphism in ischemic and hemorrhagic stroke. Clin Chim Acta. 2011;412:642-6.

9. Munshi A, Sultana S. Kaul S, Reddy BP, Alladi S, Jyothy A. Angiotensin-converting enzyme insertion/deletion polymorphism and the risk of ischemic stroke in a South Indian population. J Neurol Sci. 2008;272(1-2):132-5.

10. Khalimova KhM, Yakubova MM, Ibragimova MP. ACE gene and ischemic stroke. Nevrologiia (Tashkent). 2008; 3-4:258. [Article in Russian]

11. Gao X, Yang H, ZhiPing T. Association studies of genetic polymorphism, environmental factors and their interaction in 
ischemic stroke. Neurosci Lett. 2006;398:172-77.

12. Karagiannis A, Balaska K, Tziomalos K, Tokalaki-Nikolaidou L, Papayeoryiou A, Zamboulis C. Lack of an association between angiotensin-converting enzyme gene insertion/deletion polymorphism and ischaemic stroke. Eur Neurol. 2004;51:148-52. 13. Tuncer N, Tuglular S, Kiliç G, Sazci A, Us O, Kara I. Evaluation of the angiotensin-converting enzyme insertion/ deletion polymorphism and the risk of ischemic stroke. J Clin Neurosci. 2006;13(2):224-7.

14. Vijayan M, Chinniah R, Ravi PM, Mosses Joseph AK, Vellaiappan NA, Krishnan JI, Karuppiah B. ACE-II genotype and I allele predicts ischemic stroke among males in south India. Meta Gene. 2014;2:661-9.

15. Sierra C, Coca A, Gómez-Angelats E, Poch E, Sobrino J, de la Sierra A. Renin-angiotensin system genetic polymorphisms and cerebral white matter lesions in essential hypertension. Hypertension. 2002;39(2 Pt 2):343-7.

16. Szolnoki Z. Evaluation of the interactions of common genetic mutations in stroke. Methods Mol Med. 2005;104:241-250.

17. Zhang Z, Xu G, Liu D, Fan X, Zhu W, Liu X. Angiotensinconverting enzyme insertion/deletion polymorphism contributes to ischemic stroke risk: a meta-analysis of 50 case-control studies. PLoS One. 2012;7(10): e46495.

18. Eliseyeva MR, Khamidullaeva GA, Abdullaeva GJ, Srojidinova NZ. Genetic determinants of cardiovascular remodeling in patients with essential hypertension of Uzbek nationality. Ter Arkh.2009; 1:64-69. [Article in Russian].

19. Kurbanov RD, Kan LE, Bekmetova FM, Shek AB. The distribution of I/D polymorphic marker of the angiotensin converting enzyme and family history of coronary heart disease in Uzbeks.patients with unstable angina Uzbeks. Sibirskoe Med Obozrenie. 2012;77(5). [Article in Russian] 20. Khamidullaeva GA. Endothelial dysfunction in essential hypertension: clinical, genetic and pharmacological aspects. Abstract of PhD Thesis. Tashkent; 2010. [in Russian]

21. Czarnecka D, Kawecka-Jaszcz K, Stolarz K, Olszanecka A, Kieć-Wilk B, Dembińska-Kieć A. Genetic factors in hypertension. Angiotensin-converting enzyme polymorphism. Kardiol Pol. 2004;61(7):1-10.

22. Henskens LH, Spiering W, Stoffers HE, Soomers FL, Vlietinck RF, de Leeuw PW, Kroon AA. Effects of ACE I/D and AT1R-A1166C polymorphisms on blood pressure in a healthy normotensive primary care population: first results of the Hippocates study. J Hypertens. 2003;21(1):81-6. 